\title{
Study on the technology of strengthening concrete by impregnation with modified sodium silicate compound strengthening fluid
}

\author{
Yang Dishan ${ }^{1,}$, Yan Tongyu ${ }^{1}$, Huang Xiaoyu ${ }^{1}$, Xiong Ying ${ }^{1}$, Lin $\mathrm{Xi}^{1}$, Zhou Hong ${ }^{2}$ and Shi Jianguang ${ }^{2}$ \\ ${ }^{1}$ National Grid Fujian Electric Power Co., Ltd. Institute of Economics and Technology, Fuzhou 350012, China \\ ${ }^{2}$ School of Architecture and Civil Engineering, Xiamen University, Fujian 361005, China
}

\begin{abstract}
It is the key to the concrete repair and strengthening construction that the base concrete has a certain quality and strength. Based on the strengthening mechanism of sodium silicate,the sodium silicate was modified to develop a kind of compound strengthening liquid. Through the contrast test results of concrete impregnation. The strength of C5 concrete before and after strengthening is increased by $42.5 \%$, while the strength of $\mathrm{C} 10$ concrete is increased by $21.4 \%$, and the strength of $\mathrm{C} 15$ concrete is increased by $10 \%$.
\end{abstract}

\section{Introduction}

It is very common and serious that the durability damage of the outdoor concrete structure support in the coastal substation, which causes the aging and deterioration of concrete in different degrees ${ }^{[1,2]}$. There are four steps, base treatment, interface treatment, repair treatment and surface treatment in the repair process of durability damage ${ }^{[3]}$. The treatment of concrete base includes eliminating the defects such as floating slurry, weathering and spalling, and chiseling base to meet the requirements of certain roughness ${ }^{[47]}$, so as to ensure that repair and reinforcement materials and base concrete bond strength enough to ensure that damage does not occur at the interface. But it is difficult the concrete base treatment construction as to cause dust and other environmental problems, especially for the construction of the outdoor concrete support of the substation. Therefore, it is effective technical measures to reduce or avoid the elimination, roughen and other concrete base if we can reinforce the concrete base directly after surface cleaning, improve the quality and strength of concrete base and meet the bonding conditions between repair or reinforcement materials. So, on the basis of summarizing the research results of sodium silicate reinforced concrete, the modified sodium silicate composite reinforced concrete was developed in this paper. Through the contrast test after concrete immersion, the reinforcement effect of impregnation was studied.

\section{Research status of sodium silicate reinforced concrete technology}

Sodium silicate solution state, generally colorless or slightly colored transparent or translucent viscous liquid.
Molecular formula $\mathrm{Na}_{2} \mathrm{O} \cdot \mathrm{mSiO}_{2}$, molar ratio of silica sand to alkali, i.e. the molar ratio of $\mathrm{SiO}_{2}$ to $\mathrm{Na}_{2} \mathrm{O}$, determines the modulus $\mathrm{M}$ of sodium silicate. The modulus not only reflects the composition of sodium silicate, but also affects the physical and chemical properties of sodium silicate. Therefore, different modulus of sodium silicate has different uses ${ }^{\left[{ }^{[8]}\right.}$. Shi ${ }^{[9]}$ found that sodium silicate sodium silicate can hydrolyze at room temperature, ionize the silica gel and dehydrate and condense to form a network structure with Si-O-Si as the framework. Fan ${ }^{[10]}$ Using nano-silica soaking solution soak, PVA solution strengthening, soaking in the sodium silicate solution strengthening, sodium silicate solution immersion as well as PVA solution soak four kinds of strengthening methods for recycled aggregates for strengthening experiment, found that modified PVA solution and sodium silicate solution immersion of recycled coarse aggregate has good effect, the PVA solution concentration was $0.5 \%$, concentration of sodium silicate solution was $5 \%$ when modified effect is best, recycled concrete 28 -day strength increased by $7.2 \%$ and $23.7 \%$ respectively. In order to study the influence of inorganic surface treating agent on the surface performance and durability of airport pavement concrete, $\mathrm{Li}^{[11]}$ used sodium silicate with lithium silicate to form composite sodium silicate inorganic surface treatment agent, the inorganic surface treatment agent is coated on the surface of concrete block. The test results showed that the surface hardness of concrete reached 9.0 after 7 days.

\footnotetext{
${ }^{*}$ Corresponding author: 550818454@qq.com
} 


\section{Research and development of modified sodium silicate composite reinforcement solution and experimental study on impregnating reinforced concrete}

\subsection{Research and development of modified sodium silicate composite reinforcement solution}

The modification methods of sodium silicate mainly include enhancing the penetration ability of sodium silicate, increasing the curing strength of sodium silicate, and speeding up the curing time of sodium silicate. To enhance the penetration ability of sodium silicate is to reduce the viscosity of sodium silicate and make it easier to penetrate into the concrete. The penetration of liquid in concrete can be regarded as capillary water absorption, and the penetration depth of solution in capillary can be described by Equation (1).

$$
x=\sqrt{\frac{\sigma r \cos \theta}{2 \eta}} \sqrt{t}=k \sqrt{t}
$$

Where, $x$ is penetration depth; $\sigma$ is surface tension; $\mathrm{r}$ is pore radius; $\theta$ is the contact angle; $\eta$ is viscosity; $T$ is time; $K$ is the capillary coefficient or permeability coefficient. It can be seen from Equation (1) that, under the same conditions, the penetration depth of the solution in concrete is determined by the contact angle and interfacial energy of the solution, and the relationship between the contact angle and interfacial energy can be expressed by Young's Equation (2).

$$
\gamma_{s g}-\gamma_{s l}=\gamma \cos \theta_{1 g}
$$

Where: $\gamma_{\mathrm{sg}}$ is solid-gas interface energy; $\gamma_{\mathrm{sl}}$ is the solidliquid interface energy; $\gamma_{\mathrm{gg}}$ is the liquid-gas interface energy; $\theta$ is the solid-liquid contact angle.

According to Young's equation (2), the contact angle is affected by the solid-liquid-gas interface energy, which is determined by the liquid's surface tension. In order for the liquid to be wetted at the solid interface, it is necessary to reduce the surface tension of the liquid. The addition of chemical surfactants can effectively reduce the surface tension of the liquid, $\mathrm{Li}^{[12]}$ pointed out that the surfactant is a compound composed of two groups with different properties: hydrophilic group and hydrophobic group. Hydrophilic group is generally non-polar hydrocarbon chains, while hydrophobic groups are generally polar groups such as $-\mathrm{OH},-\mathrm{COOH}$ and $-\mathrm{SO}_{3}$. When the surfactant is dissolved in water, its hydrophilic end will be attracted into the water molecules, and its hydrophobic end is repelled, so the molecules in the surfactant on the surface of water orientation, resulting in water solution surface tension greatly reduced, thereby greatly improving the wetting ability of the solution.

In addition, the penetration depth can be increased by reducing the viscosity of sodium silicate, and the viscosity can be adjusted by changing the concentration of sodium silicate. The influence of concentration and modulus on the viscosity of sodium silicate is plotted by $\mathrm{Zhu}^{[13]}$. The viscosity of sodium silicate increases linearly when it exceeds the critical value. Since the modified sodium silicate module used is 3.4 and the critical concentration is $37 \%, 2.7$ liters of water should be added for dilution per liter of sodium silicate to minimize its viscosity while maintaining the concentration of sodium silicate as much as possible.

The curing strength of sodium silicate is generally related to the curing conditions and additives in sodium silicate. The addition of additives in sodium silicate can also improve the curing strength and bonding strength of sodium silicate. There are four curing ways of sodium silicate including heating hardening, microwave hardening, carbon dioxide hardening, alcohol and ester hardening ${ }^{[14]}$. The mechanism of hardening of sodium silicate by heating is mainly that the heating will dehydrate the sodium silicate, which will have different hardening processes at different temperatures. When the temperature reaches more than 100 degrees, the $\mathrm{Si}-\mathrm{OH}$ bond in the sodium silicate will dehydrate and associate with each other and form Si-O-Si bond, so the sodium silicate will form a stable material with $\mathrm{Si}-\mathrm{O}-\mathrm{Si}$ chain structure. Microwave hardening is the use of microwave to accelerate the hardening of sodium silicate. The temperature will rise rapidly after the sodium silicate absorbs the energy of microwave. The silica molecules and water molecules in the sodium silicate will oscillate at a high speed at the same time. The colloidal particles will accelerate the movement and under the influence of heat, and quickly form a dense and small glass-like network structure of colloidal particles. $\mathrm{CO}_{2}$ gas hardening refers to the rapid hardening of sodium silicate by blowing $\mathrm{CO}_{2}$. Under the action of $\mathrm{CO}_{2}$ gas, sodium silicate can react with $\mathrm{CO}_{2}$ to form silica gel. At the same time, $\mathrm{CO}_{2}$ has a good drying effect, which can quickly dry sodium silicate. The water of silica gel is evaporated and dehydrated to form solid $\mathrm{SiO}_{2}$, which is finally condensed and hardened. The hardening of alcohols and esters refers to the addition of organic esters can react with sodium silicate, so that the modulus of sodium silicate increases, and further dehydration of sodium silicate occurs hardening. Studies have shown that adding polyols in sodium silicate can improve the bonding strength of sodium silicate after curing.

The mechanism is not exactly the same although the four methods can make the sodium silicate hardening. The compressive strength of sodium silicate obtained by microwave hardening method is higher, while that obtained by alcohol and esters hardening method has better bonding property. $\mathrm{Li}^{[15]}$ found that adding a small amount of sodium tetraborate can improve the hardening strength of sodium silicate, and the bond strength increases with the increase of sodium tetraborate content. Sodium tetraborate or borax, molecular formula $\mathrm{Na}_{2} \mathrm{~B}_{4} \mathrm{O}_{7} \cdot 10 \mathrm{H}_{2} \mathrm{O}$ is a very important boron mineral and boron compound. It is usually a white powder containing colorless crystals and soluble in water. Sodium tetraborate presents a tetrahedral form because its structure formula is similar with sodium silicate, both of them are tetravalent boron atoms or silicon atoms connected with three oxygen atoms. Therefore, adding sodium tetraborate in sodium silicate can form a composite glass network 
with sodium silicate and improve the integrity of the network, so as to improve the curing strength of sodium silicate.

It is necessary to control the dosage of curing agent because sodium silicate penetrating into concrete takes a certain time as well as adding curing agent can not make sodium silicate solidify too fast so as to lose liquidity. When sodium silicate is added to sodium silicate, it can react with the hydrolysate of sodium silicate. The hydrolysis reaction of sodium silicate is shown in equation (3).

$$
\mathrm{Na}_{2} \mathrm{SiO}_{3}+3 \mathrm{H}_{2} \mathrm{O}=2 \mathrm{NaOH}+\mathrm{Si}(\mathrm{OH})_{4}
$$

The product $\mathrm{Si}(\mathrm{OH})_{4}$ is also called orthosilicate, generally written as $\mathrm{H}_{4} \mathrm{SiO}_{4}$, but written as $\mathrm{Si}(\mathrm{OH})_{4}$ is easier to understand. Adding sodium fluosilicate to sodium silicate can react with $\mathrm{NaOH}$, the hydrolyzed product of sodium silicate. The reaction formula is shown in Equation (4).

$$
\mathrm{Na}_{2} \mathrm{SiF}_{6}+6 \mathrm{NaOH}=\mathrm{Na}_{2} \mathrm{SiO}_{3}+6 \mathrm{NaF}+3 \mathrm{H}_{2} \mathrm{O}
$$

By combining the two equations above, the total equation can be obtained, as shown in Equation (5).

$$
2 \mathrm{Na}_{2} \mathrm{SiO}_{3}+\mathrm{Na}_{2} \mathrm{SiF}_{6}+6 \mathrm{H}_{2} \mathrm{O}=6 \mathrm{NaF} \downarrow+3 \mathrm{Si}(\mathrm{OH})_{4}
$$

It can be concluded from the total reaction that after adding $\mathrm{NA}_{2} \mathrm{SiF}_{6}$, it reacts with $\mathrm{NaOH}$, thus accelerating the hydrolysis of sodium silicate. $\mathrm{Si}$ in $\mathrm{Na}_{2} \mathrm{SiO}_{3}$ and $\mathrm{Na}_{2} \mathrm{SiF}_{6}$ all generates the orthosilicate monomer $\mathrm{Si}(\mathrm{OH})_{4}$. $\mathrm{Si}(\mathrm{OH})_{4}$ is an elastic colloid, and it is also the material that finally plays a bonding role. Orthosilicate can be dehydrated and condensed to form a network structure material with Si-O-Si chain. The NaF generated by the whole reaction is insoluble material, so if the sodium silicate is solidified in the concrete, the NaF generated can not only fill the gap after the solidification of sodium silicate, but also fill the pores in the concrete, which is of positive significance to enhance the curing strength of sodium silicate and concrete strength. Therefore, the addition of $\mathrm{Na}_{2} \mathrm{SiF}_{6}$ not only shortens the curing time of sodium silicate, but also improves the curing strength of sodium silicate.

Based on the control of sodium silicate concentration, the selection of surfactants and additives, and the control of curing agent dosage, the sodium silicate is modified to improve its permeability and wetting ability, and improve the curing strength, bond strength and concrete strength, so as to achieve the purpose of providing concrete durability and strength. The material preparation of modified sodium silicate composite reinforcing solution selected the sodium tetraborate product produced by Tianjin Zhiyuan Chemical Reagent Co., Ltd. The molecular formula is $\mathrm{Na}_{2} \mathrm{~B}_{4} \mathrm{O}_{7} \cdot 10 \mathrm{H}_{2} \mathrm{O}$, the molecular weight is 381.38 , and the purity is $99.5 \%$. The molecular formula of sodium dodecyl sulfate produced by Beijing Jintong Letai Chemical Products Co., Ltd. is $\mathrm{C}_{12} \mathrm{H}_{25} \mathrm{SO}_{3} \mathrm{Na}$. Due to the negative charge of sulfonic acid
group-SO3 on the left side, it belongs to anionic surfactant. The molecular formula of sodium fluorosilicate produced by Pingxiang Baishi Chemical Reagent Co., Ltd. is Na2SiF6 with purity of $99.0 \%$.

\subsection{Manufacture of concrete test blocks and impregnating reinforced concrete}

The main materials of concrete test block are silicate cement, water, coarse aggregate and fine aggregate. The cement is $\mathrm{P} \cdot \mathrm{O} 32.5$ ordinary Portland cement, which meets the national standard GB175-1999<Portland cement, ordinary Portland cement $>$. The flexural strength of $3 \mathrm{~d}$ and $28 \mathrm{~d}$ is $4.0 \mathrm{MPa}$ and $7.6 \mathrm{MPa}$, respectively. The compressive strength of $3 \mathrm{~d}$ and $28 \mathrm{~d}$ is $18.8 \mathrm{MPa}$ and 37.4 $\mathrm{MPa}$, respectively. The fine aggregate used is manufactured sand from Quanzhou, Fujian, and the apparent density is $2680 \mathrm{~kg} / \mathrm{m}^{3}$. According to the requirements of $\mathrm{GB} / \mathrm{T}$ 14684-2011 <Sand for construction $>$, the percentage of sieve residue meets the requirements. The coarse aggregate is gravel from Fujian Xiamen, and the continuous gradation is $5 \sim 25 \mathrm{~mm}$. According to the requirements of GB/T 14685-2011< Construction pebbles and gravels $>$, the cumulative screening percentage of gravel aggregate meets the standard requirements. Water is tap water. Three concrete blocks with different mix proportions of $\mathrm{C} 5, \mathrm{C} 10$ and $\mathrm{C} 15$ were designed. According to $<$ Selection table of concrete sand ratio $>$ in JGJ 55 - $2011<$ Specification for mix design of ordinary concrete $>$, the sand ratio was determined to be $45 \%$, and then the amount of coarse and fine aggregate was determined by the absolute volume method. Three kinds of concrete mix ratio see table 1 .

Table1. Mix ratio of three kinds of concrete test blocks.

\begin{tabular}{|c|c|c|c|c|}
\hline \multirow{2}{*}{$\begin{array}{c}\text { Concrete } \\
\text { label }\end{array}$} & \multicolumn{4}{|c|}{ Material dosage $/\left(\mathrm{kg} / \mathrm{m}^{3}\right)$} \\
\cline { 2 - 5 } & cement & water & sand & the stone \\
\hline $\mathrm{C} 5$ & 156 & 195 & 915 & 1,118 \\
\hline $\mathrm{C} 10$ & 207 & 195 & 894 & 1,092 \\
\hline $\mathrm{C} 15$ & 256 & 195 & 875 & 1,069 \\
\hline
\end{tabular}

In order to make the modified sodium silicate reinforcing liquid penetrate deep into the concrete as far as possible, the concrete test block was infiltrated by impregnation method. Three different strength concrete test blocks were put into the impervious PE plastic bag, and then the matched reinforcing liquid was added. The opening was closed to ensure that the reinforcing liquid was not evaporated, and the environment temperature was $20{ }^{\circ} \mathrm{C}$ and the relative humidity was $70 \%$ (figure 1 ). 

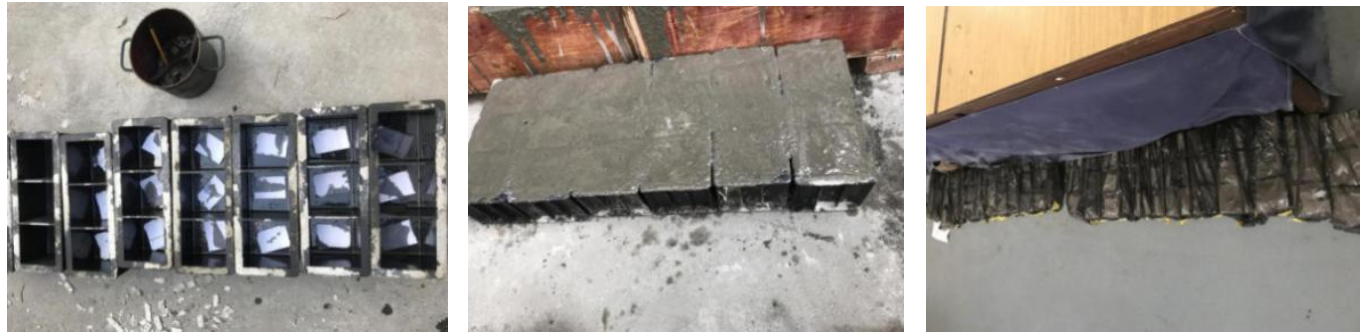

Figure 1. Concrete test mould, test block and impregnation method.
(a) test mould;
(b) test block;
(c) Impregnation method.

\section{Properties of concrete reinforced by modified sodium silicate composite reinforcing solution}

\subsection{Compressive strength of concrete reinforced with modified sodium silicate composite reinforcement solution}

It can be seen from the comparison of the compressive strength of concrete reinforced by modified sodium silicate composite reinforcing liquid (Fig. 2, Table 2) that the strength of $\mathrm{C} 5$ grade concrete increases by $42.5 \%$, that of 10 grade concrete increases by $21.4 \%$, and that of $\mathrm{C} 15$ grade concrete increases by $10 \%$. Sodium silicate is the liquid form of sodium silicate, which contains more silicate, and free $\mathrm{Ca}$ after entering the concrete2+. In addition, the three-dimensional mesh material with Si-O$\mathrm{Si}$ chain is generated when the modified sodium silicate composite reinforcing liquid is solidified, so the reinforcing effect is better.

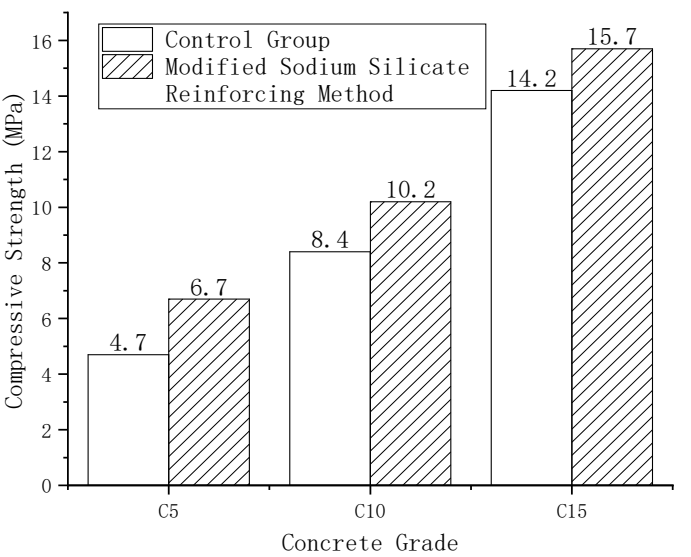

Figure 2. Comparison of compressive strength of concrete before and after reinforcement.

Table2. Compressive strength of concrete before and after reinforcement with modified sodium silicate composite reinforcement solution.

\begin{tabular}{cccccc}
\hline \multirow{2}{*}{ group } & Concrete label & \multicolumn{3}{c}{ Test block number /MPa } & \multirow{2}{*}{ Average/MPa } \\
\cline { 3 - 5 } & & $\mathbf{1}$ & $\mathbf{2}$ & $\mathbf{3}$ & \\
\hline Modified sodium silicate & $\mathrm{C} 5$ & 4.8 & 4.8 & 4.6 & 4.7 \\
$\begin{array}{c}\text { composite reinforcing } \\
\text { liquid before reinforcing }\end{array}$ & $\mathrm{C} 10$ & 8.6 & 8.1 & 8.6 & 8.4 \\
& $\mathrm{C} 15$ & 14.7 & 13.8 & 14.0 & 14.2 \\
Modified sodium silicate & $\mathrm{C} 5$ & 6.7 & 6.7 & 6.7 & 6.7 \\
composite reinforcing & $\mathrm{C} 10$ & 10.4 & 10.4 & 10.0 & 10.2 \\
liquid after reinforcing & $\mathrm{C} 15$ & 15.9 & 15.7 & 15.7 & 15.7 \\
\hline
\end{tabular}

\subsection{Microstructure of Modified Sodium silicate Composite Reinforcement}

The microstructure shown in the concrete after reinforcement by modified sodium silicate composite reinforcement solution can be divided into two categories. The first category is the dense network structure formed by the condensation of integral sodium silicate itself, such as the left part of the scanning electron microscope after 10,000 times magnification ( Fig. 3 ). The second is the $\mathrm{C}-\mathrm{S}-\mathrm{H}$ gel produced by the reaction of silicate in sodium silicate with $\mathrm{Ca}(\mathrm{OH})_{2}$ in concrete. It can be seen that the reinforcement mechanism of sodium silicate for concrete substrate can be divided into two categories. The first is its own condensation curing, and the second is the reaction with calcium hydroxide that does not contribute to the strength in concrete to generate calcium silicate hydrate that plays a major role in the strength. From the analysis of the reinforcement mechanism and curing mechanism of modified sodium silicate composite reinforcement solution, the reinforcement can be divided into two aspects. The first aspect is the reaction of silicate ions in sodium silicate and calcium ions in concrete to generate calcium silicate. On the other hand, the selfcuring of sodium silicate forms a polymer with $\mathrm{Si}-\mathrm{O}-\mathrm{Si}$ chain. Therefore, the modified sodium silicate composite reinforcement solution improves the internal microstructure of concrete and the reinforcement effect is good. 

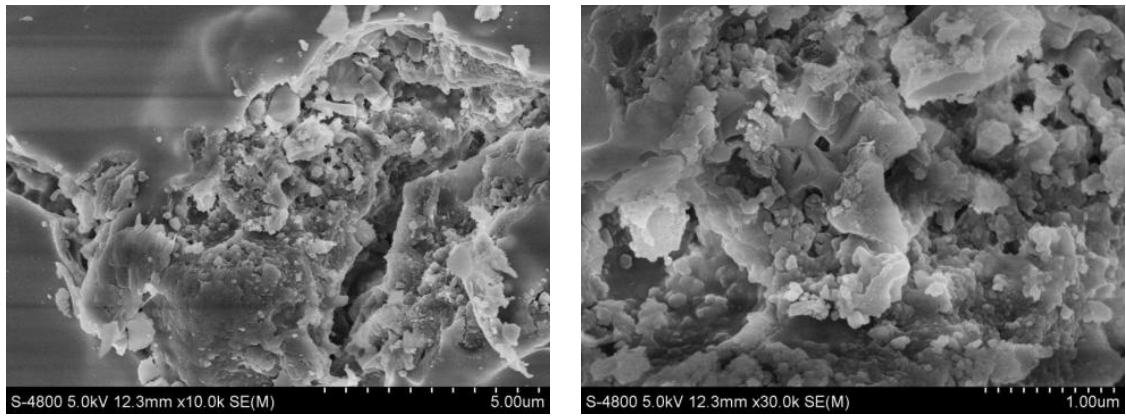

Figure 3. Microstructure of concrete reinforced by modified sodium silicate composite reinforcing solution. (a) 10000-fold; (b)300-fold

\section{Conclusion}

The sodium silicate was modified by controlling the concentration of sodium silicate, selecting surfactants and additives, and controlling the dosage of curing agent. The permeability and wetting ability were improved, and the curing strength, bond strength and concrete strength were improved. The modified sodium silicate composite reinforcement solution was prepared by adding sodium tetraborate, sodium dodecyl sulfate, sodium fluosilicate and other materials. Through the comparative test of concrete impregnation, it can be found that:

(1) Modified sodium silicate composite reinforcement solution has a very significant reinforcement effect on low-strength concrete. The strength of C5 concrete before and after reinforcement increased by $42.5 \%, \mathrm{C} 10$ concrete by $21.4 \%$, and C15 concrete by $10 \%$.

(2) It can be seen from the microstructure of the reinforcement solution, it can be seen that the reinforcement effect comes from the reaction of silicate ions in sodium silicate and calcium ions in concrete to form calcium silicate, and the glass itself is solidified to form a polymer with $\mathrm{Si}-\mathrm{O}-\mathrm{Si}$ chain.

\section{References}

1. Yang Dishan, Lin Xi, Shi Jianguang et al. Research summary of durability damage and strengthening of outdoor concrete facilities in coastal substation [A ]. Paper collection of 2020 Industrial Architecture Academic Exchange ( Volume I ) [ C ]. Zhongye Architectural Research Institute Co., Ltd : Industrial Architecture Journal, $2020: 7$.

2. Xia Xiaojian, Jin Yan, Qiao Hanwen, et al. Survey on Corrosion of Power Transmission and Transformation Equipment [ $\mathrm{J}$ ]. Corrosion science and protection technology, 2019,31 ( 02 ) : 121-127.

3. Hui Yunling, Yue Qingrui. The durability damage and repair of concrete structures [ $\mathrm{C}$ ], the sixth national conference on building identification and reinforcement. The National Technical Committee for Building Identification and Reinforcement Standards, 2002.

4. JGJ / T 238-2011, Technical specification for interface guniting on concrete base $[\mathrm{S}]$.
5. JGJ/T 259-2012, Technical specification for rehabilitation and protection of concrete structures durability $[\mathrm{S}]$.

6. GB 50367 - 2013, Code for design of strengthening concrete structure $[\mathrm{S}]$.

7. GB 50550-2010, Code for acceptance of construction quality of strengthening building structures [ $\mathrm{S}$ ].

8. Wang Kun, Kang Yong, Ai Jiang. Modification, Hardening Mechanism and Application Prospect of Sodium Silicate Materials [ J ]. Foshan ceramics, 2016,26 ( 05 ):

9. Shi Caijun, Wang Yue, Pan Xiaoying, et al. Advances in Inorganic Surface Treatment of Concrete [ $\mathrm{J}$ ]. Materials reports, 2017,31 ( 13 ) : 113-119.

10. Fan Yuhui, Niu Haicheng, Zhang Xianggang. Experimental study on the modification of recycled aggregate concrete by nano- $\mathrm{SiO}_{2}[\mathrm{~J}]$. Concrete, 2017, $000(007): 92-95$.

11. Li Xiaorong. Effect of inorganic surface treatment agent on performance of airport pavement concrete [J]. Hunan Communication Science and Technology, 2019,45 ( 03 ) : 71-74.

12. Li Yiming. Study on modification of sodium silicate and its application in protection of ancient ivory [D ]. Chengdu University of Technology, 2007.

13. Zhu Chunxi, Lu Chen. Understanding Process of Sodium Silicate Hardening [ J ]. Inorganic Chemicals Industry, 2001 ( 01$): 22-25+2$.

14. Hu Caiying, Zhou Yanming, Luo Hong, et al. The Analysis of the Solidification Mechanismes \& Water Resistance Improvement Accesses of the Water-Glass [ J ]. Ceramics, 2011 ( 08 ) : 18-21.

15. Li Yiming, Ye Qiaoming. Study on the modification effect of sodium tetraborate on sodium silicate $[\mathrm{J}]$. Guangdong Weiliang Yuansu Kexue, 2006 ( 10 ) : 66 $-68$ 